Sharif University of Technology
Scientia Iranica
Transactions A: Civil Engineering
SCIENTIA
IRAN I CA

\title{
Tubular Web RBS connection to improve seismic behavior of moment-resisting steel frames
}

\author{
S.M. Zahrai ${ }^{\mathrm{a}}$, S.R. Mirghaderi ${ }^{\mathrm{a}}$ and A. Saleh ${ }^{\mathrm{b}, *}$ \\ a. School of Civil Engineering, College of Engineering, The University of Tehran, Tehran, P.O. Box 11155/4563, Iran. \\ b. Department of Civil Engineering, Islamic Azad University, Professor Hesabi Branch, Tafresh, P.O. Box 3951736167, Iran. \\ Received 17 October 2015; received in revised form 29 June 2016; accepted 29 October 2016
}

\author{
KEYWORDS \\ Cyclic behavior; \\ Moment-resisting steel \\ frames; \\ Rigid connection; \\ Reduced beam \\ section; \\ Tubular Web RBS \\ (TW-RBS).
}

\begin{abstract}
A new type of Reduced Beam Section (RBS) connection, called "Tubular Web RBS (TW-RBS)", is proposed in this research. TW-RBS is made by replacing a part of web with a tube at the expected location of the beam plastic hinge. In addition to an analytical study, the proposed section is numerically studied under cyclic load using ABAQUS finiteelement software, and a test specimen is used for the calibration of numerical results. The results show that using TW-RBS not only creates a ductile fuse far from the beamto-column connection components, but it also increases story drift capacity up to $9 \%$. Furthermore, the tubular web, like corrugated sheet, can improve both the out-of-plane stiffness of the beam longitudinal axis and the flange stability condition due to the smaller width-to-thickness ratio of the beam flange in the plastic hinge region. Thus, the tubular web improves lateral-torsional buckling stability of beam. On the other hand, the tubular web provides a better condition than other accordion web with sharp corners in terms of low-cycle fatigue, because change of direction of strain in arc shape of the tubular web section is smaller than the accordion web with sharp corners.
\end{abstract}

(C) 2017 Sharif University of Technology. All rights reserved.

\section{Introduction}

The experiences gained from the earthquake effects, such as the Northridge and Kobe earthquakes, posed serious challenges in seismic behavior of steel structures at the international level. The most extensive study has been done by the SAC committee leading to the results published in the set of FEMA 350 [1]. The concentrated tensions on the welded areas of flange, web, and connection vulnerability in high ductility demands were considered as two main critical factors

\footnotetext{
*. Corresponding author. Tel./Fax: +98216111-2273 E-mail addresses: mzahrai@ut.ac.ir (S.M. Zahrai); rmirghaderi@ut.ac.ir (S.R. Mirghaderi); aboozar.saleh@ut.ac.ir (A.Saleh)
}

of failure. A common way to resolve this issue is to reduce the ductility demand and related concentrated tensions in these areas. Thus, different methods and ideas have been provided in order to reduce the demands of the beam-to-column connection. A basic strategy of this method is to intentionally reduce the section of the connected beam which results in the formation of plastic hinge at the reduced cross-section. Furthermore, local reduction decreases the demand of the components of connection. It reduces the damages made to the components of connection including panel zone, continuity plates, and related welds at a rigid connection. The studies on the reduced beam section can be categorized as follows:

\subsection{RBS connections}

RBS connection with a dog-bone configuration was 
initiated by a European company, named Arbed, and was patented in the USA in 1992. SAC committee [2] studied the results of 45 tests on RBS connection after the Northridge Earthquake during 1996 to 1998. The main variables in these tests are the shape of flange cut (straight cut, tapered cut, or radius cut), depths of columns and beams, and web connection. According to the results, the radius cut RBS connection showed successful behavior; the connection behavior depended on the beam depth; bolted and welded web connections had relatively similar behaviors. Chen and Chao (2001) [3] examined the effects of concrete slab on moment connection by the reduced section. They showed that the ratio of positive to negative moment capacity can be 1.18 with the presence of slab.

Adopting a statistical study, cyclic instability of RBS connections was investigated by Uang and Fan in 2001 [4]. Nakashima and Kanao (2002) [5] studied analytically and numerically the lateral torsional instability and lateral bracing effects of wide-flange steel beams subjected to cyclic loading. Jay Shen et al. (2002) [6] analyzed the RBS connected to deep columns and investigated the effects of slab through a numerical approach. This study showed that the lateral beams and floor slab provide suitable lateral bearing for the beam.

Jones et al. (2002) [7] experimentally investigated the effects of panel zone, concrete slab, and also the effect of the web connection type. Roeder (2002) [8], summarizing SAC committee's research, expressed that development of shear deformation in panel zone in the RBS connections can also enhance the ductility demand on the column flange weld. Ricles et al. (2002) [9] presented that panel zone in the RBS connections plays an important role in connection behavior provided for using balanced panel zone in an analytical and experimental research report. Lee et al., 2005 [10], using eight full-scale tests, showed that strong panel zone leads to dissipating total energy in the reduced region; so, this area has significant local buckling and lateral-torsional buckling which leads to a twisted column.

Moslehi Tabar and Deilami (2005) [11] numerically studied the instability of RBS connection, concentrating on the effect of plasticity shear panel in columns. Their results indicated that not only does the rigid shear panel keep the panel zone in the elastic range, but it also causes instability in the beam cyclic behavior. Zhang and Ricles (2006) [12,13] demonstrated that concrete floor supports beam top flange and increases the ultimate load in the plastic hinge, which is not included in design procedures. Han and Moon (2009) [14] showed that if the span-to-depth ratio is less than 10 and if the beam flange bendingmoment contribution is less than $70 \%$ of the beam flexural strength, then using web bolted connection is not recommended. Pachoumis et al. (2010) [15] studied cyclic behavior of RBS moment connections through experimental and numerical analysis. They showed that using the RBS connection in European sections requires changing the RBS geometric parameters.

\subsection{Reducing the web height}

In another study, Wilkinson et al. (2006) [16] evaluated a new detail by which the web height reduction near the connection of beam-to-column is achieved. The experimental results approved that the plastic rotation capacity is more than $5 \%$.

\subsection{Connection with web reduction}

In FEMA 350 [1], a new type of reduced connection has been proposed in which the demand reduction at the column face is provided through making a circle hole in the web near the connection. The size of hole is such that the yielding occurs along the span and the connection remains in the elastic range. Rao and Kumar (2006) [17] studied a connection with rectangular hollow in web, entitled Rectangular Hollow Sections (RHS). In their study, channel beam to channel column connection was used. Yang and Yang (2009) [18] studied the circular hole in web sections as well as a built-up beam numerical model with different loading distances of $2,3,4$, and 5 meters and varying circular holes radius.

\subsection{Connection with accordion web}

The flexural behavior of a beam with corrugated web considerably differs from that with a flat web. This different behavior is derived from the difference between the natures of the flat sheet and corrugated sheet. Flat sheet in the in-plane stress has an isotropic behavior, although stiffness of corrugated sheet in $x$ and $y$ directions is completely different. In the longitudinal direction, stiffness is sharply reduced. This small stiffness in corrugated sheet causing deformation under load is similar to opening and closing accordion. This behavior is called accordion behavior. So, by using accordion web in beams due to the lack of strain on the web, and thereby little participation of corrugated web in flexure resistance, the ultimate bending capacity can be determined only based on the beam flange plastic capacity while web effect can be ignored. In this case, the whole shear is mainly tolerated by the corrugated web. Previous studies have also shown that there is no interaction between the flexural behavior and shear behavior of beams with corrugated web [19]. Mirghaderi et al. (2010) [20] discussed and evaluated bending beam connection of reduced cross-section by corrugated web in an experimental and analytical study. Two symmetric angles were considered in two test samples with respect to the web as corrugated sheet to execute removed web accommodation and create a cross-section as Accordion Web RBS (AW-RBS). The results of both 
tests were correlated without reducing resistance up to $8 \%$ story drift. Saleh et al. (2016) [21] experimentally studied a kind of accordion-web RBS connection in which part of the flat web of the beam is replaced by a steel tube. Based on the experimental results, the tubular web in the plastic hinge region improves lateraltorsional buckling stability of the beam, such that only local buckling of the beam flange at the center of the reduced section was observed during the tests.

\subsection{Heat-treated Beam Section (HBS)}

The technique involves reducing the strength of specified regions of the beam flanges by exposing them to high temperatures followed by slow cooling as studied by Morrison et al. (2015) [22]. Contrary to RBS, HBS connection does not sacrifice elastic stiffness or buckling resistance. They tested two largescale connections modified with the HBS technique leading to the promotion of yielding and plastic hinge development in the heat-treated regions with specimens attaining inter-story drifts as high as $6 \%$ without weld or near-weld fracture.

Usual RBS moment connection is one of the most economical and practical prequalified connections, but according to the previous studies, this connection is weak in terms of assessing beam instabilities, such as web and flange local buckling and subsequent lateral torsional buckling. Such instabilities cause degradation in the connection strength at large rotation demands. On the other hand, beam connection with a reduction in web area or web height reduces shear strength at the plastic hinge location. Heat-treated beam section is better than the other purposed connections, but seems expensive as heat processing is used after fabrication. Connection with accordion web can improve both outof-plane stiffness of the beam longitudinal axis and the flange stability condition due to the smaller widthto-thickness ratio of beam flange. Thus, conditions of beam stability would be better in connection with accordion web at larger rotation demands.

Parallel to the connection with accordion web in this paper, a new web RBS connection called "TWRBS" is proposed for steel moment-resisting frames. In the proposed connection, the beam bending capacity is reduced using a pipe instead of a flat web at the expected location of the beam plastic hinge in the vicinity of the beam-to-column connection. The tubular web provides even a better condition than AW-RBS connection in low-cycle fatigue by changing sharp corners of angles to arc shape of the tubular web section. In this regard, the present study aims to analytically and numerically investigate the seismic behavior and cyclic response of the new proposed connection. It is noteworthy that a specimen test was used for the calibration of numerical results in this study.

\section{The proposed connection (TW-RBS) design}

\subsection{Determining the appropriate location of the $T W$ - RBS}

Connection design approach is based on the 2010 AISC seismic provisions [23]. In order to reduce demand and decrease the failure of beam welded to column connection and surrounding material, the maximum moment demand at the column face must be lower than the nominal plastic strength in that specific point. Therefore, as illustrated in Figure 1, the maximum moment generated at the column face $\left(M_{f}\right)$ can be obtained from the image of the maximum expected moment established in the center of the reduced beam section $\left(M_{\mathrm{TW}-\mathrm{RBS}}\right)$ as follows:

$$
M_{f}=M_{\mathrm{TW}-\mathrm{RBS}} \frac{(L+e)}{L},
$$

where $L$ is the distance between the centerline of reduced beam section to the middle span. If compared to the seismic demand, the gravity load on the beam is assumed small, and then the moment distribution is linear. Maximum expected moment created in the center of reduced beam section $\left(M_{\mathrm{TW}-\mathrm{RBS}}\right)$ based on seismic criteria is defined as follows:

$$
M_{(\mathrm{TW}-\mathrm{RBS})}=1.1 R_{y} Z_{(\mathrm{TW}-\mathrm{RBS})} F_{y},
$$

where $Z_{\text {TW-RBS }}$ is the plastic section modulus of the corrugated region, and $R_{y}$ is the difference between the minimum specified yield strength $\left(F_{y}\right)$ and the expected yield strength. Maximum moment demand at the column face ratio to the nominal plastic strength is calculated as follows:

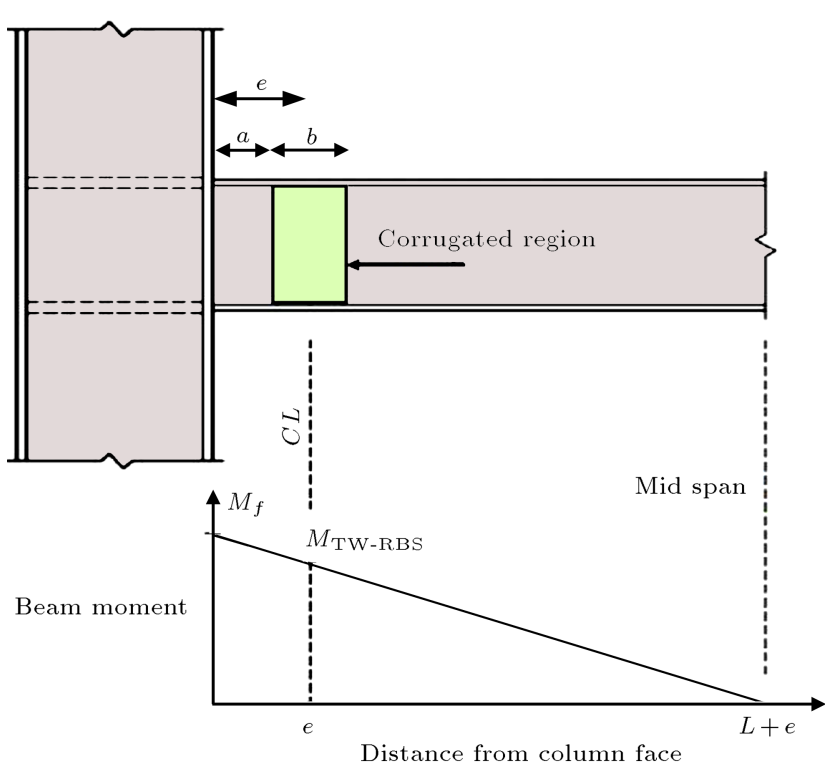

Figure 1. Bending moment gradient for seismic loading. 


$$
\begin{aligned}
\alpha & =\frac{M_{f}}{Z_{b} R_{y} F_{y}}=\frac{M_{(\mathrm{TW}-\mathrm{RBS})} \frac{(L+e)}{L}}{Z_{b} R_{y} F_{y}} \\
& =\frac{1.1 R_{y} Z_{(\mathrm{TW}-\mathrm{RBS})} F_{y} \frac{(L+e)}{L}}{Z_{b} R_{y} F_{y}} \\
& =\frac{1.1 Z_{(\mathrm{TW}-\mathrm{RBS})}(L+e)}{Z_{b} L} .
\end{aligned}
$$

In the equation above, $Z_{b}$ is the plastic modulus in the unreduced beam section at the column face. In order to reduce demand and failure risk in welded connection of beam and the column face, the value of $\alpha$ must be lower than 1 . The recommended value for this parameter in the design of common reduced beams is 0.9 [24]. Therefore, the plastic modulus of reduced and unreduced beam sections and the length of cantilevered beam $(L+e)$ determine the appropriate distance from the center of the reduced section to the column face.

\subsection{Substructure and the choice of dimensional parameters}

The proposed subassembly used in similar experimental studies investigated by Mirghaderi et al. [20] was chosen to confirm beneficial behavior of the connection. It consists of interior connection with beams attached to the column opposite faces. In this subassembly, half of the parts of lower and upper columns were chosen as vertical elements, and half of the beam was chosen as horizontal elements.

For modeling the connection, box-column (built- up $200 \times 160 \times 10$ ) and IPE180 were chosen, respectively, for column and beam, as shown in Table 1 . The geometrical dimensions are $2150 \mathrm{~mm}$ for the vertical members, acting as the columns, and $3290 \mathrm{~mm}$ (distance between the rollers boundary condition of two beams) for the horizontal members, behaving as the beams. The selected sections satisfy width-thickness ratio of seismically compact section.

The distance of center of tube to the column face and also diameter of tube come from Table 2 and Eq. (4):

As it can be seen, with considering the allowed range for $e$, the diameter of tube can be determined from Eq. (4):

$$
D=2(e-a) \text {. }
$$

So, by allowing for $a=5.35$, it gives a value of $7.3 \mathrm{~cm}$ for tube outside the diameter. The thickness of available steel pipe in the market according to DIN2440 is $5.5 \mathrm{~mm}$, which is known with nominal diameter of $65 \mathrm{~mm}(2-1 / 2 \mathrm{inch})$.

\subsection{Determining the expected moment in plastic hinge location $\left(M_{T W-R B S}\right)$}

According to the reduced section plastic modulus, the expected moment is specified in the beam plastic hinge location and the condition of weak beam-strong column is controlled, as presented in Table 3 in which expected yielding stress of material $\left(F_{y e}=R_{y} F_{y}=1.5 \times 2400=\right.$ 3600 ) has been used. Sufficient safety factor for column face demand is provided $(\alpha=0.888)$.

Table 1. Determining the beam and column specifications.

\begin{tabular}{ccccccc}
\hline Member & Section & $\begin{array}{c}\boldsymbol{A} \\
\left(\mathbf{m}^{\mathbf{2}} \times \mathbf{1 0}^{-\mathbf{4}}\right)\end{array}$ & $\begin{array}{c}\boldsymbol{d} \\
\left(\mathbf{m} \times \mathbf{1 0}^{-\mathbf{2}}\right)\end{array}$ & $\begin{array}{c}\boldsymbol{b}_{\boldsymbol{f}} \\
\left(\mathbf{m} \times \mathbf{1 0}^{-\mathbf{2}}\right)\end{array}$ & $\begin{array}{c}\boldsymbol{t}_{\boldsymbol{f}} \\
\left(\mathbf{m} \times \mathbf{1 0}^{-\mathbf{2}}\right)\end{array}$ & $\begin{array}{c}\boldsymbol{t}_{\boldsymbol{w}} \\
\left(\mathbf{m} \times \mathbf{1 0}^{-\mathbf{2}}\right)\end{array}$ \\
\hline Beam & IPE180 & 23.9 & 18 & 9.1 & 0.8 & 0.53 \\
Column & $200 \times 160 \times 10$ & 64.0 & 18 & 14 & 1.0 & 1.0 \\
\hline
\end{tabular}

Note: $A$ : cross-section area; $d$ : depth of section; $b_{f}$ and $t_{f}$ : width and thickness of flange; and $t_{w}$ : thickness of web.

Table 2. Determining the reduced section of dimensional parameters.

\begin{tabular}{ccccccc}
\hline Section & $\begin{array}{c}Z_{b} \\
\left(\mathbf{m}^{\mathbf{3}} \times \mathbf{1 0}^{-\mathbf{6}}\right)\end{array}$ & $\begin{array}{c}Z_{\mathbf{T W}-\mathrm{RBS}} \\
\left(\mathbf{m}^{\mathbf{3}} \times \mathbf{1 0}^{-\mathbf{6}}\right)\end{array}$ & $\begin{array}{c}\boldsymbol{L}+\boldsymbol{e} \\
\left(\mathbf{m} \times \mathbf{1 0}^{-\mathbf{2}}\right)\end{array}$ & $\begin{array}{c}\boldsymbol{e} \\
\left(\mathbf{m} \times \mathbf{1 0}^{-\mathbf{2}}\right)\end{array}$ & $\begin{array}{c}\text { Allowed range of } \boldsymbol{e} \\
\mathbf{0 . 5 d}<\boldsymbol{e}<\boldsymbol{d} \\
\left(\mathbf{m} \times \mathbf{1 0}^{-\mathbf{2}}\right)\end{array}$ & $\begin{array}{c}\text { Allowed range of } \boldsymbol{a} \\
\mathbf{0 . 5} \boldsymbol{b}_{\boldsymbol{f}}<\boldsymbol{a}<\mathbf{0 . 7 5} \boldsymbol{b}_{\boldsymbol{f}} \\
\left(\mathbf{m} \times \mathbf{1 0}^{-\mathbf{2}}\right)\end{array}$ \\
\hline IPE180 & 166 & 131.44 & 154.5 & 9 & $9<e<18$ & $4.55<a<6.83$ \\
\hline
\end{tabular}

\begin{tabular}{|c|c|c|c|c|c|c|c|c|c|}
\hline $\begin{array}{c}Z_{\mathrm{TW}-\mathrm{RBS}} \\
\left(\mathrm{m}^{3} \times 10^{-6}\right)\end{array}$ & $\begin{array}{c}M_{\mathrm{TW}-\mathrm{RBS}} \\
(\mathrm{kN}-\mathrm{m})\end{array}$ & $\begin{array}{c}L \\
\left(\mathrm{~m} \times 10^{-2}\right)\end{array}$ & $\begin{array}{c}e \\
\left(\mathrm{~m} \times 10^{-2}\right)\end{array}$ & $\begin{array}{c}M_{f} \\
(\mathrm{kN}-\mathrm{m})\end{array}$ & $\begin{array}{c}Z_{b} F_{y e} \\
(\mathrm{kN}-\mathrm{m})\end{array}$ & $\alpha$ & $\begin{array}{cc}e+d_{c} / 2 & \sum M_{p b} \\
\left(\mathrm{~m} \times 10^{-2}\right) & (\mathrm{kN}-\mathrm{m})\end{array}$ & $\sum_{(\mathbf{k N}-\mathbf{m})} M_{p c}$ & $\sum M_{p c} / \sum M_{p b}$ \\
\hline 131.44 & 52.05 & 145.5 & 9 & 55.27 & 59.76 & 0.925 & 117.7 & 205.44 & 1.75 \\
\hline
\end{tabular}

Note: $Z_{b}$ : Plastic modulus of the unreduced section; $Z_{\mathrm{TW}}$-RBS: Plastic modulus of the reduced section (Appendix);

$L+e$ : Length of beam; and $e$ : Distance from the center of the reduced section to the column face (Eq. (3)).

Table 3. Beam design control at the column face.

Note: $M_{\mathrm{TW}-\mathrm{RBS}}$ : expected moment in plastic hinge location; $M_{f}$ : beam moment at the column face location;

$\alpha=M_{f} / Z_{b} F_{y e}:$ moment ratio at the column face;

$\sum M_{p b}=\sum M_{c}=2 M_{f} \times(L+e+d c / 2) /(L+e)$ : beam moment at the center of column;

$\sum M_{p c}=\sum Z_{c} F_{y c}$ : column plastic moment. 


\subsection{Controlling beam shear}

In corrugated sheets, shear buckling is controlled by the interaction of the buckling mode obtained from interaction of local and global buckling modes. Elastic local buckling shear stress can be calculated using Eq. (5) [25]:

$$
\tau_{c r, l}^{e}=k_{1} \frac{\pi^{2} E}{12\left(1-\nu^{2}\right)}\left(\frac{t_{w}}{\omega}\right)^{2} .
$$

In Eq. (5), $E$ is the Young elastic modulus; $\nu$ is the Poisson ratio, and $\omega$ is the maximum value of horizontal width and diagonal width (shown by "a" and "c", respectively, in Figure 2) of corrugated sheet; $t_{w}$ is the thickness of corrugated sheet; $k_{l}$ is the local shear buckling coefficient defined as follows [25]. In Eq. (6), $h_{w}$ is height of the corrugated web sheet:

$$
k_{l}=5.34+4\left(\frac{\omega}{h_{w}}\right)^{2} \text {. }
$$

Global buckling of corrugated sheet is calculated based on stability equations as follows [25]:

$$
\tau_{c r, G}^{e}=k_{G} \frac{\pi^{2} E}{12\left(1-\nu^{2}\right)}\left(\frac{t_{w}}{h_{w}}\right)^{2} .
$$

General shear buckling coefficient, $k_{G}$, is defined as follows [25]:

$$
k_{G}=\frac{36 \beta}{\pi^{2} \sqrt{\eta}}\left[2\left(\left(\frac{d}{t_{\omega}}\right)+1\right)\left(1-\nu^{2}\right)\right]^{3 / 4},
$$

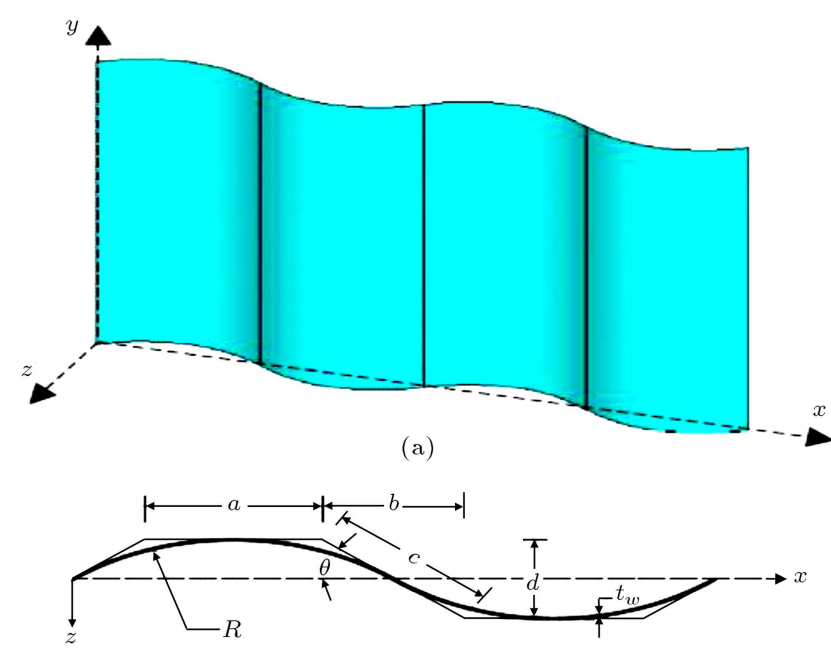

(b)

Figure 2. Geometry of arc-shaped corrugated sheet [25]. where $\beta$ is 1 and 1.9 for the simple and rigid edge connections, respectively; $\eta$ defines length reduction factor which is calculated through $(a+b) /(a+c), d$ is the depth of corrugated sheet, and $\nu$ is assumed to be 0.3 in this study.

The equation for shear buckling strength interaction proposed by Eldib [26] can be used for unusual corrugated sheets such as arcs. This equation was proposed based on Pachoumis's experimental study on 40 trapezoidal sheets [27]:

$$
\left(\frac{1}{\tau_{c r}}\right)^{n}=\left(\frac{1}{\tau_{c r, B}}\right)^{n}+\left(\frac{1}{\tau_{y}}\right)^{n}
$$

where value of $n$ is 4 for local buckling and 1.5 for general buckling. Also, $\tau_{c r, B}^{e}$ is the minimum value of localized and general shear buckling strengths.

In this study, shear buckling strength interaction for arc-shaped corrugated sheets was calculated using the equations above. Beam shear was controlled in the plastic hinge along tubular web and its outside. Shear demand was obtained according to the capacity method corresponding to the formation of plastic hinges to which gravity shear was also added. By removing gravity load in the numerical model, the shear will be constant in beam. The local and general buckling strengths of tubular webs are presented in Table 4; the expected yielding stress of material has also been used. Furthermore, $\Phi_{v}=0.9$ and shear stress to yielding limit of $\tau_{y}=0.577$ and $F_{y}=138.5 \mathrm{MPa}$ are considered.

Calculations of shear control are provided in Table 5. According to the global and local buckling resistance calculated over yielding shear limit, it can be used in Eq. (9) to measure the interaction buckling strength; buckling is resisted by shear yielding stress. So, we have:

$$
\begin{aligned}
& \left(\frac{1}{\tau_{c r}}\right)^{1.5}=\left(\frac{1}{\tau_{y}}\right)^{1.5}+\left(\frac{1}{\tau_{y}}\right)^{1.5}, \\
& \tau_{c r}=\frac{\tau_{y}}{3 \sqrt{2^{2}}}=87.2 \mathrm{MPa} .
\end{aligned}
$$

\begin{tabular}{|c|c|c|c|c|c|c|c|c|c|c|c|}
\hline $\begin{array}{c}d \\
\left(\mathrm{~m} \times 10^{-2}\right) \\
\end{array}$ & $\begin{array}{c}a \\
\left(\mathrm{~m} \times 10^{-2}\right) \\
\end{array}$ & $\begin{array}{c}b \\
\left(\mathrm{~m} \times 10^{-2}\right) \\
\end{array}$ & $\begin{array}{c}c \\
\left(\mathrm{~m} \times 10^{-2}\right) \\
\end{array}$ & $\begin{array}{c}w \\
\left(\mathrm{~m} \times 10^{-2}\right) \\
\end{array}$ & $\begin{array}{c}t_{w} \\
\left(\mathrm{~m} \times 10^{-2}\right)\end{array}$ & $\begin{array}{c}h_{w} \\
\left(\mathrm{~m} \times 10^{-2}\right)\end{array}$ & $\eta$ & $k_{l}$ & $\begin{array}{c}\tau_{c r, l}^{e} \\
(\mathrm{MPa})\end{array}$ & $k_{G}$ & $\begin{array}{c}\tau_{c r, G}^{e} \\
(\mathrm{MPa})\end{array}$ \\
\hline 7.3 & 7.3 & 0.0 & 7.3 & 7.3 & 0.55 & 16.4 & 0.5 & 6.13 & 6384.3 & 392.5 & 80993 \\
\hline
\end{tabular}

\subsection{Designing panel zone and continuity plates}

Due to the moment demand at the column face, this demand at panel zone was compared with its capacity.

Table 4. Local and general buckling strengths of tubular web.

Note: $d, t_{w}$ and $h_{w}$ : Depth, thickness and height of tube. 
Table 5. Shear control of flat and tubular webs.

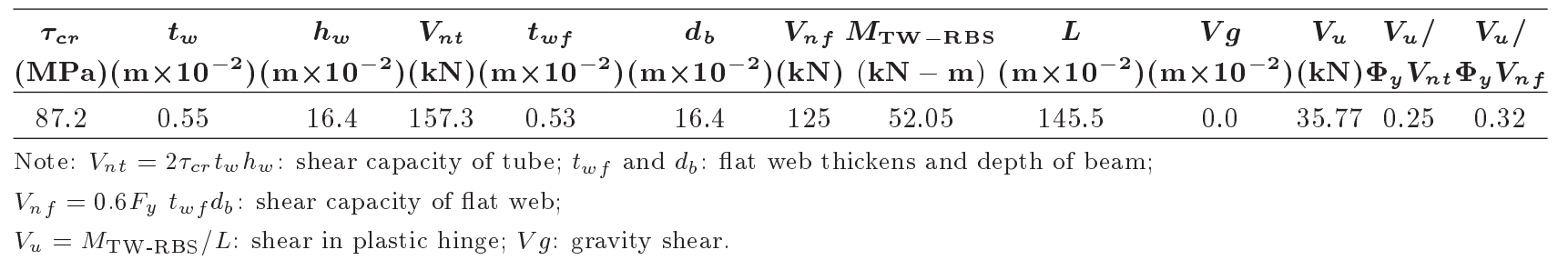

In these calculations, the shear strength reduction factor of $\Phi_{\nu}=1.0$ was considered. Minimum thickness of shear panel was obtained from Eq. (12):

$$
t_{z} \geq \frac{w_{z}+d_{z}}{90} .
$$

In Eq. (12), $w_{z}$ and $d_{z}$ are the width and depth of panel zone, respectively; so, by substituting 18 and $18 \mathrm{~cm}$ in Eq. (12), the minimum thickness of the panel zone is $0.4 \mathrm{~cm}$. This control criterion is established according to the thickness of box-column.

Continuity plates of $180 \times 140 \times 15 \mathrm{~mm}^{3}$ were used in the panel zone. This sheet not only tolerates the imposed tensile and compressive force from the beam flange, but also conversely converts the axial force to shear force in panel zone, since the established lengthto-width ratio is greater than 1.5 on this sheet. In addition, width-to-thickness ratio in $b / t<800 / \sqrt{F_{y}}$ is also satisfied. Thus, the proposed model is already defined and can be simulated with ABAQUS software.

\section{Finite element modeling}

Connections analysis is carried out using a threedimensional finite-element model in ABAQUS6.10. Given the assumption of the SHELL behavior of components in this model, deformable SHELL is defined for all components. Four-node tetrahedral element with six degrees of freedom (three translational degrees and three rotational degrees) was used for meshing the components. Mesh sizes of all components are similar (maximum dimension $1.5 \mathrm{~cm}$ ) except for beam flange (maximum dimension $1.25 \mathrm{~cm}$ ). All the regarded elements are square-shaped. This model focuses on investigating the model behavior; while connections weld is not explicitly modeled, however, degrees of freedom in connection zone are bound together with Tie constraints (Figure 3).

\subsection{Material properties}

Due to the fact that materials are supposed to exceed their linear range, the analysis should be done considering nonlinear behavior. St37 steel with kinematic hardening and bilinear response curve was used to define the mechanical properties, where the slope of the elastic behavior is (Young modulus) $E=2.03 e^{+6} \mathrm{~kg} / \mathrm{cm}^{2}$ and the slope nonlinear behavior is obtained by connecting yield point $\left(\varepsilon_{y}, F_{y}\right)$ to failure point $\left(\varepsilon_{u}, F_{u}\right)$ on stressstrain curve. Poisson ratio for steel is 0.3 in all analyses.

\subsection{Definition of load type and analysis}

The standard solver of ABAQUS software (ABAQUS/Standard) was used for analyzing the model. In the load section, supports were defined by setting up boundary conditions. Furthermore, cyclic loading was imposed on the structure by defining boundary conditions as a displacement on top of the column based on the 2010 AISC Seismic Provisions [23]. The model investigated by ABAQUS was loaded to reach $9 \%$ story drift. The loading history consisted of six cycles at $0.375 \%, 0.5 \%$, and $0.75 \%$ total story drift angles, respectively. The next four cycles involved $1 \%$ story drift, followed by two cycles where each would successively increase drift percentages (i.e., 2, 3, 4...\%).

Boundary condition for the bottom of the column was defined by fixing the degree of freedom in 3 directions. Roller support was defined at a distance of $154.5 \mathrm{~cm}$ from the column face by fixing degree of freedom in vertical direction. To define lateral support, out-of-plane displacement of beam web was fixed at 45 and $135 \mathrm{~cm}$ from the side of the column. Also, the column was fixed with a lateral support in its upper half.

\section{Numerical results}

\subsection{Expression of results}

Lateral force-story drift cyclic curve is presented in Figure 4(a) for the proposed connection. The drift is obtained by dividing lateral displacement at the top of column to the column height. Also, Figure 4(b) provides the story drift-moment curve of beam at the column face. The moment at the column face is calculated through equilibrium in sub-structure. Increasing demand on these curves is due to subjecting material in strain hardening area. Plastic story drift versus normalized moment curve at the column face is also presented in Figure 4(c). Plastic story drift is obtained by subtracting the elastic story drift from the total story drift. The moment at the column face is normalized to beam nominal flexural capacity until the additional resistance of structures is estimated.

The results of the proposed model satisfy the 2010 


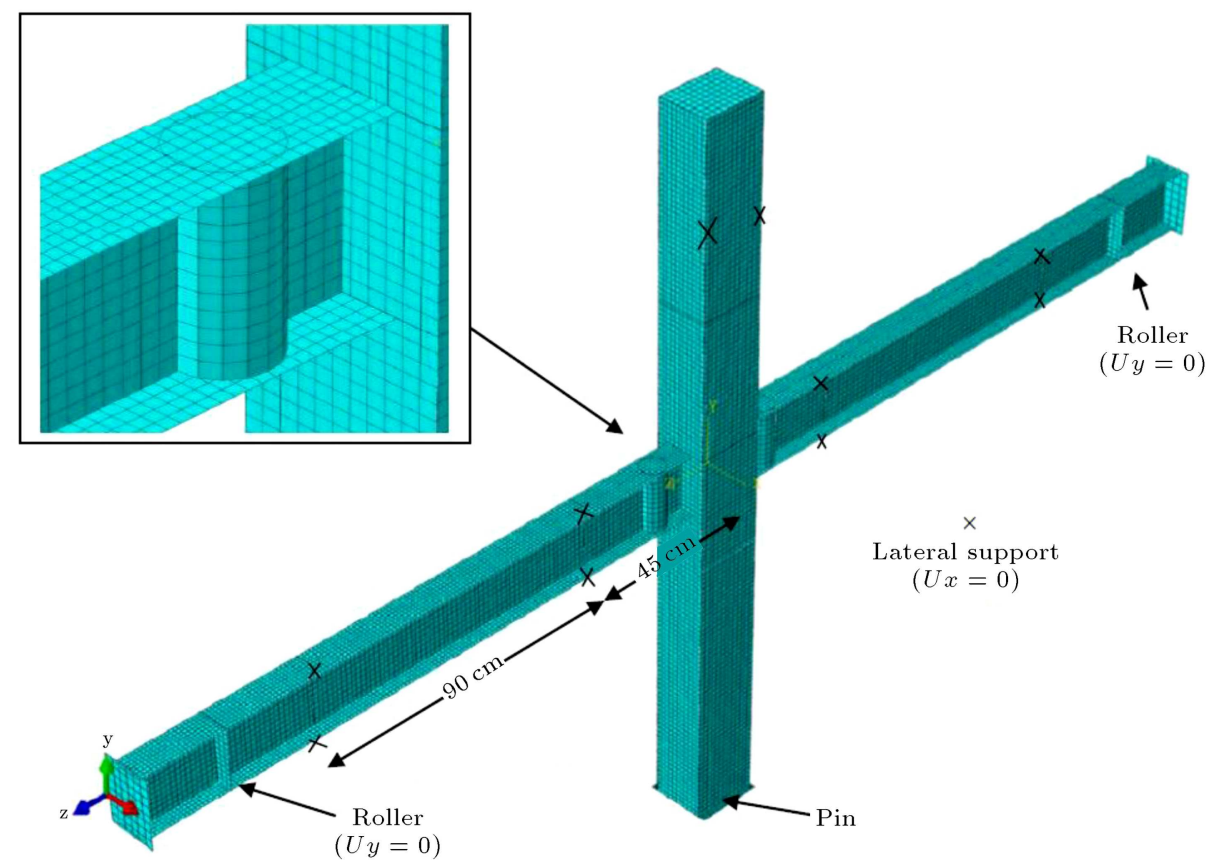

(a) Finite elements mesh

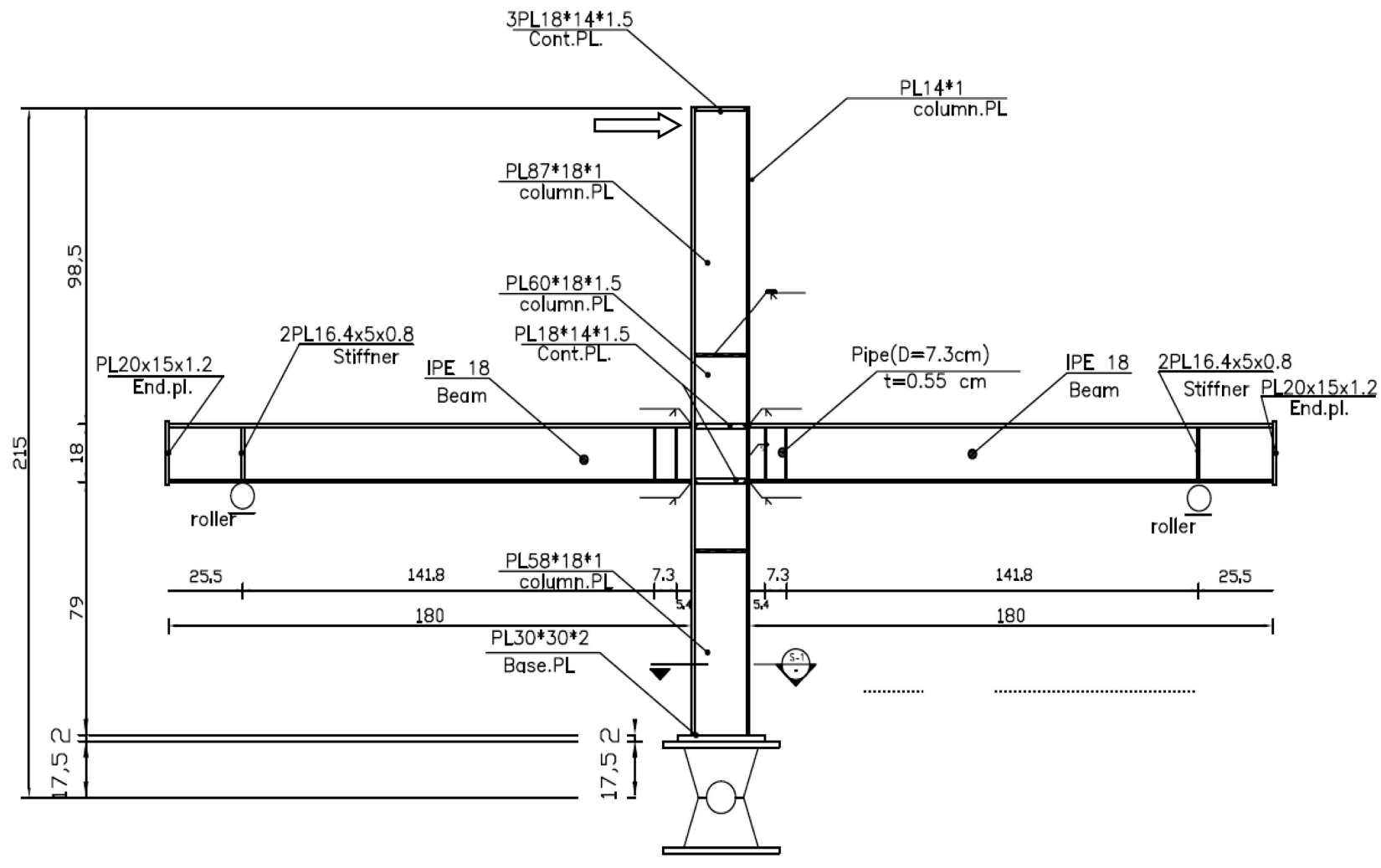

(b) Geometry of proposed connection

Figure 3. Finite-element modeling for the proposed TW-RBS connection.

AISC seismic provisions' [23] acceptance criteria to confirm that special moment frame connection tolerates at least 0.03 radian story drift, and the flexural capacity of the specimen at the column face should not be less than $80 \%$ of the beam plastic moment at 0.04 radian story drift. The proposed connection provides a stable cyclic behavior without strength reduction up to $9 \%$ story drift.

The von-Mises stress and strain contours at 0.06 radian story drift are illustrated in Figure 5 for both 


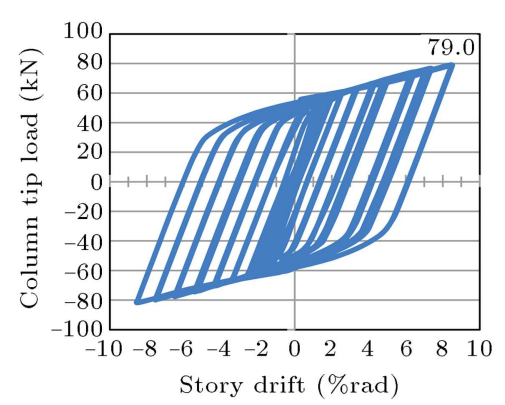

(a) Column tip force versus story drift

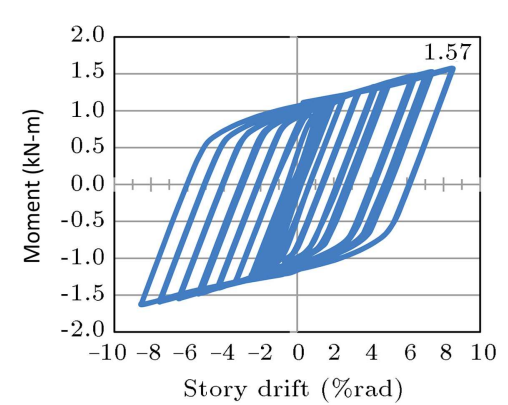

(b) Moment of beam at the column face versus story drift

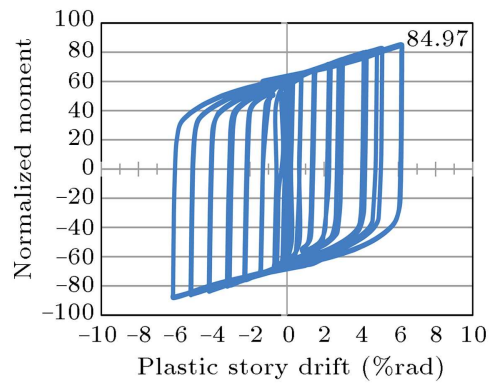

(c) Normalized moment of beam at the column face versus plastic story drift

Figure 4. Numerical results of the proposed model.

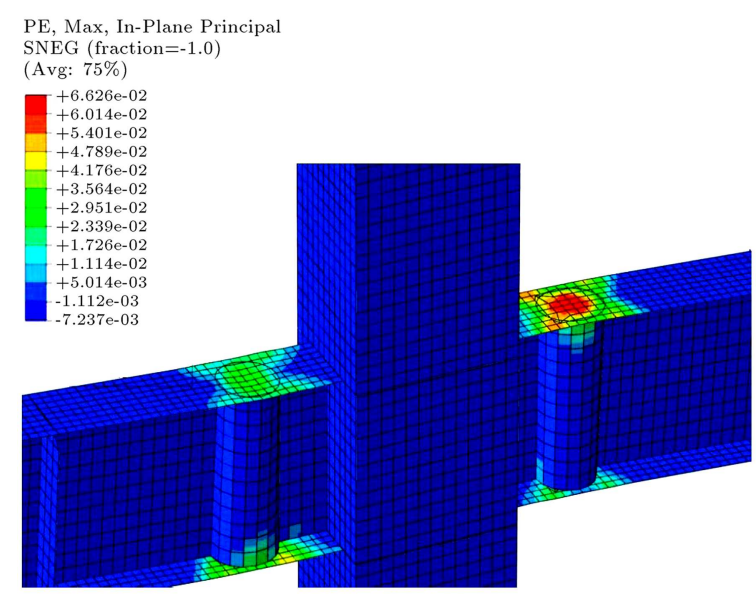

(a) Plastic strain

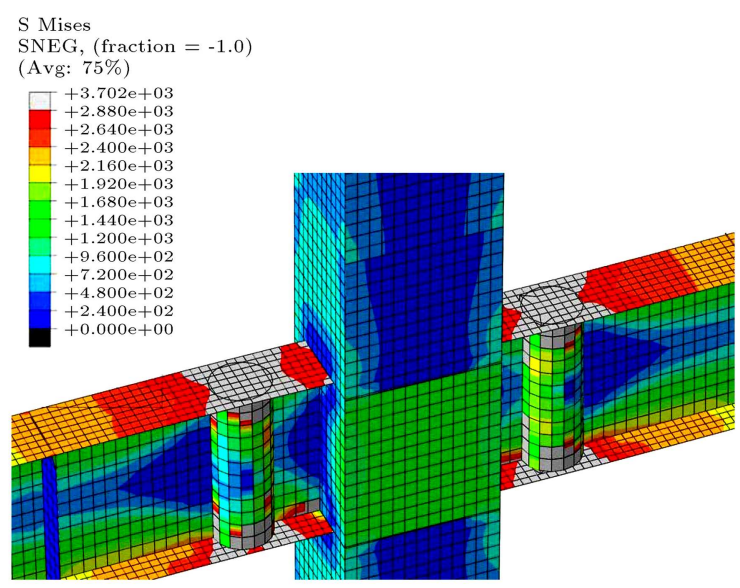

(b) Stress

Figure 5. Von-Mises stress and strain contours at 0.06 radian story drift.

positive and negative bending moments. The stress is shown by units of $\mathrm{kg} / \mathrm{cm}^{2}$. Gray color represents the yielding area, and tension contour shows formation of plastic hinge at the center of corrugated area. Flange tension near column face is lower than that in the place of plastic hinge formation. Studying the tension distribution in the corrugated web indicates that the value of tension in corrugated web is much lower than that in beam flange.

The results show that the hinge is formed at the accordion area while the plastic strain in the surrounding corrugated area has far less intensity, and the rest of area remains elastic. This reduction in strain demand at the column face and full penetration welds in beam-to-column connection significantly reduce the risk of failure at the full penetration welds.

\subsection{Results verification}

Only numerical studies may not be sufficient to support the TW-RBS connection. Cyclic plastic deformation, low cycle fatigue endurance, and the behavior of the welds without cyclic tests are unknown on TW-RBS connection. Then, for validation/calibration purposes of the numerical model, experimental test has been carried out to study the behavior of TW-RBS moment connections. All dimensions and design of connection are according to what already mentioned for the numerical model. Lateral force-story drift cyclic curve is presented in Figure 6 for TW-RBS test specimen compared with the numerical study. As shown in Figure 6, TW-RBS test specimen provides a stable cyclic behavior without strength reduction up to $8 \%$ story

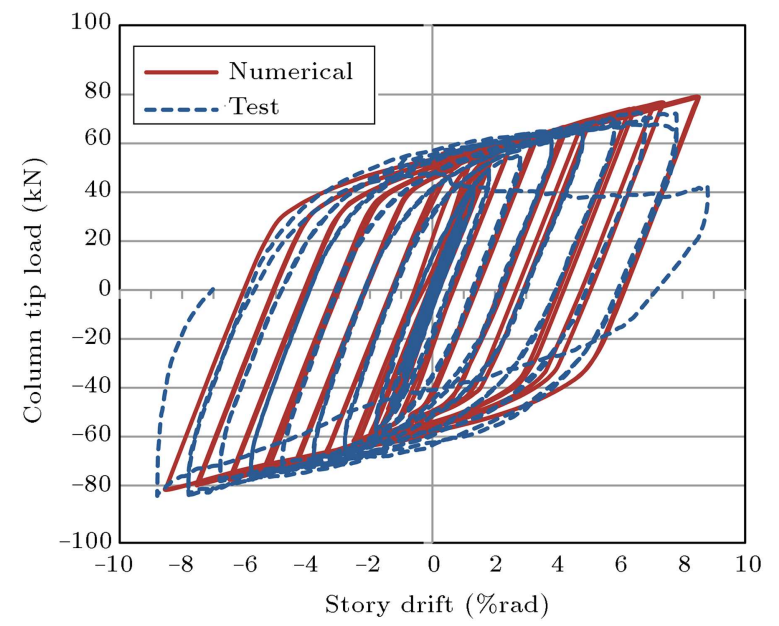

Figure 6. Column tip force versus story drift for TW-RBS test specimen and numerical study. 


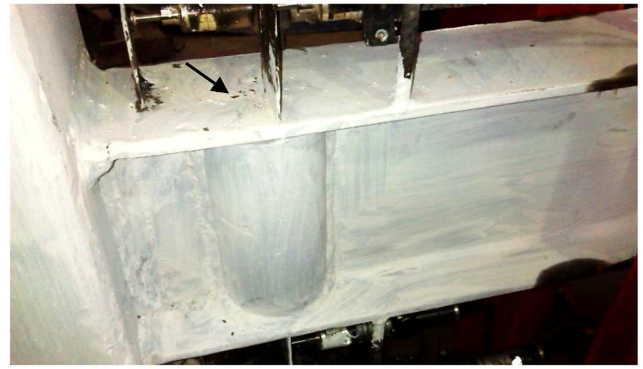

(a) First yielding at the center of the reduced region at $1.5 \%$ story drift

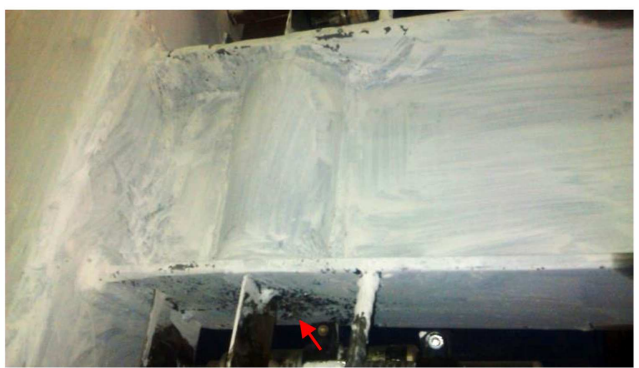

(c) Local buckling in the right beam at $4 \%$ story drift

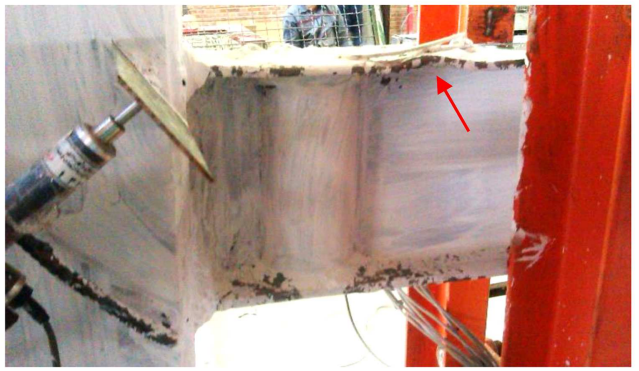

(e) Lateral-torsional buckling in the left beam at $7 \%$ story drift

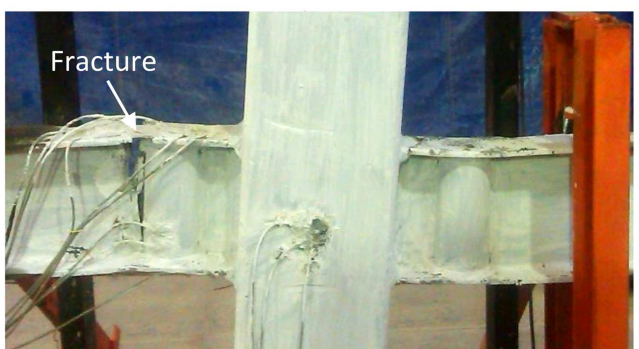

(g) Fracture in the left beam at $9 \%$ story drift

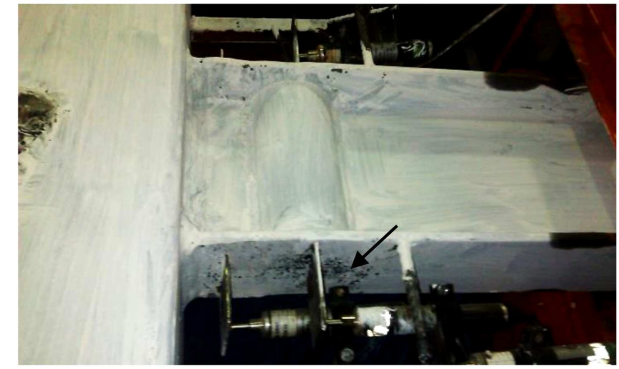

(b) The extension of the yielding at $2 \%$ story drif

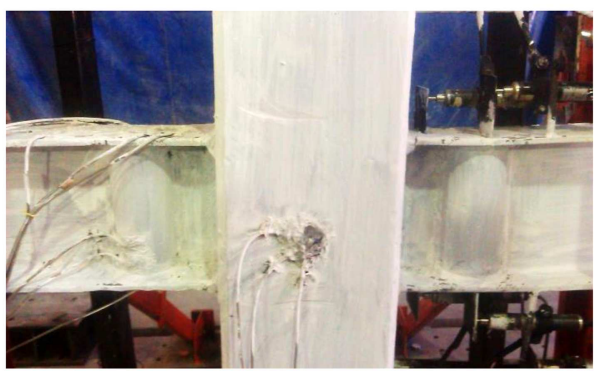

(d) Local buckling at $5 \%$ story drift
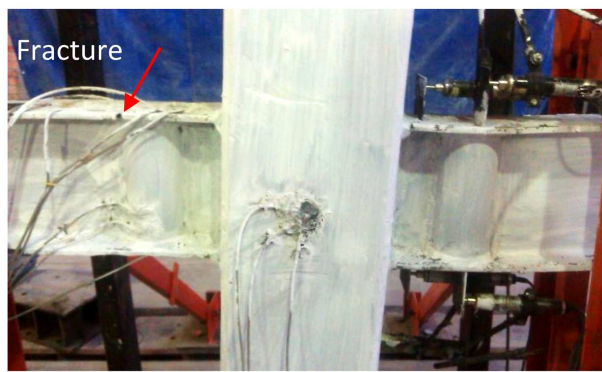

(f) Fracture in the left beam at $8 \%$ story drift

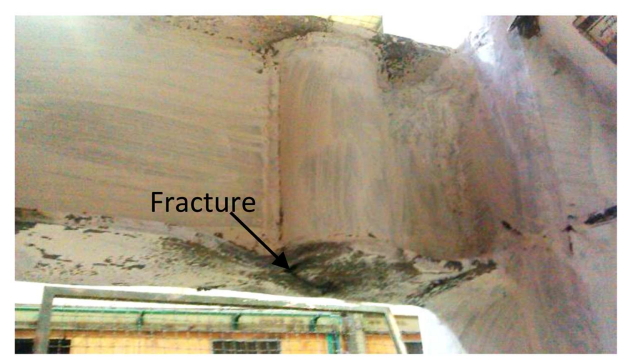

(h) Fracture in the right beam at $9 \%$ story drift

Figure 7. TW-RBS test specimen results.

drift satisfying the 2010 AISC seismic provisions [23] and FEMA [1] acceptance criteria up to $9 \%$ story drift while also validating the numerical model.

According to the test observations, first, yielding emerged on the beam flanges at the center of the reduced region during the first cycle of $1.5 \%$ story drift cycles, as shown in Figure 7(a). It spread over the entire reduced region and extended toward the column face and beam end during next story drifts (Figure 7(b)). Flange local buckling was detected in the reduced region on the both sides of beam following the $4 \%$ story drift, as shown in Figure $7(\mathrm{c})$, and the amplitude of flange local buckling increased at the next story drifts (Figure $7(\mathrm{~d})$ ). The yielding at the tubular web extended into the beam depth in the $6 \%$ story drift. In the first cycle of $7 \%$ story drift, lateraltorsional buckling of beam appeared in the top flange of left beam immediately after the reduced region, as shown in Figure $7(\mathrm{e})$. In the first cycle of $8 \%$ story drift, the crack was initiated in the top flange of left beam immediately after the reduced region, as shown in Figure $7(\mathrm{f})$. The crack progressed to the middle of 
flange and fracture was initiated in the connection weld of tubular web to flat web in this part during the second cycle of $8 \%$ story drift. The cracks progressed down into connection of the tubular web to flat web during the first cycle of $9 \%$ story drift as shown in Figure $7(\mathrm{~g})$. In the following second half of the first cycle of $9 \%$, the cracks and rupture were initiated in the bottom flange of right beam, exactly in the reduced region as shown in Figure 7(h). According to the test, low cycle fatigue cannot happen at tubular webs and lateral-torsional buckling stability maintains up to high story drift.

\section{Result comparison of TW-RBS versus AW-RBS}

The connection proposed by Mirghaderi et al. [20] was used in this section in order to compare the results. As explained in the literature, their connection was a kind of reduced section using accordion web created by double angles $50 \times 50 \times 4$ placed in IPE180 (Figure 8 ) with the same subassembly with the proposed TWRBS connection. Therefore, it was considered as a suitable choice for comparison purposes.

\subsection{Evaluation of numerical analysis observations at different story drifts}

In order to have a better assessment of the proposed model results, numerical and experimental results at different story drifts on TW-RBS model were compared with the obtained experimental results of AWRBS [20], as detailed in Table 6.

According to the results, in TW-RBS, local buckling of compression flange in the reduced section has been created at $4 \%$ story drift, while in the AW-RBS connection, buckling is noticed outside of the reduced section between reduced section area and the column face. The TW-RBS connection satisfies AISC seismic provisions [23] and FEMA [1] acceptance criteria up to $9 \%$ story drift, while the AW-RBS connection satisfies acceptance criteria up to $8 \%$. Also, TW-RBS provides a better condition in terms of low-cycle fatigue than AW-RBS because the crack and rupture at TW-RBS were finally initiated in the flange, but crack was initiated in the angles at beam web in AW-RBS.

\subsection{Evaluation of strain in numerical analysis} In order to investigate the plastic hinge region, the maximum plane strain was found on three points on the beam flange axis, including the center of the reduced section, i.e. a point near the reduced section at a distance of $4.5 \mathrm{~cm}$ from the column face, another point in the beam-to-column connections, and the last point on tubular web in the middle of pipe at its contact with flange, as shown in Figure 9. They are divided by yield strain to become the normalized strain.

The beam flange in the reduced section has high strain, as shown in Figure 9, indicating that the plastic strains are concentrated in this location. The flange of beam around the reduced region also has high strain level, whereas corrugated web experiences lower strain. The results show that the plastic hinge has occurred at the section having the corrugated web and its center matches the center of corrugated web area. Moreover, flange at beam to column connection has the lowest level of strain compared to other parts, confirming demand reduction assumption at this location.

For AW-RBS, normalized strain of the flange at the center of the reduced area at 0.03 radian story drift was obtained 16 , while a value of 25 was obtained for the analytical results of TW-RBS model, as shown in Figure 9, representing a higher strain level for the proposed model at the same story drift.

The strain envelope of top flange in a longitudinal section of beam is illustrated in Figure 10. Evaluating the values presented in the curve shows that strain of flange in the reduced section zone of the proposed model is larger than those at other locations.

For AW-RBS, normalized strains at 0.02, 0.03, and 0.04 radian story drifts in the reduced section zone were obtained 9,13 , and 15 , respectively, whereas these
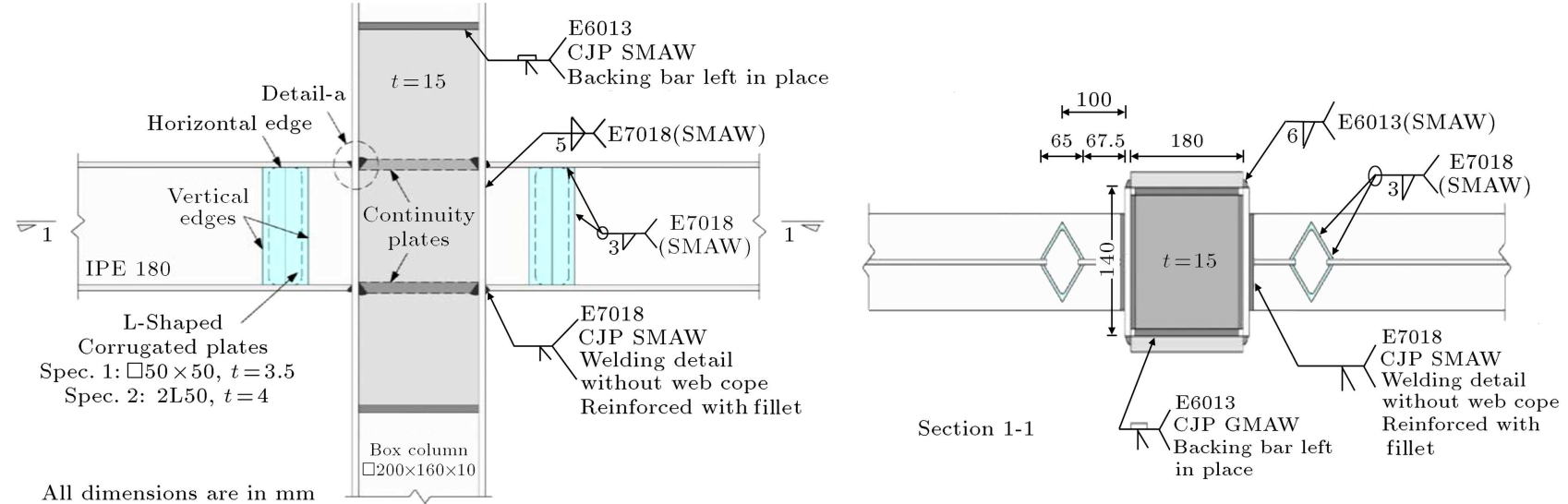

Figure 8. AW-RBS test specimen's details by Mirghaderi et al. [20]. 
Table 6. Comparison of numerical results of the proposed model and experimental results of AW-RBS model.

\begin{tabular}{|c|c|c|}
\hline $\begin{array}{l}\text { Experimental and numerical } \\
\text { study of TW-RBS model }\end{array}$ & $\begin{array}{l}\text { Experimental and numerical } \\
\text { study of AW-RBS model }\end{array}$ & Story drift \\
\hline $\begin{array}{l}\text { The first yeilding emerged at the center of the } \\
\text { corrugated region during the first cycle. }\end{array}$ & $\begin{array}{l}\text { The first yeilding emerged at the center of the } \\
\text { corrugated region during the first cycle. }\end{array}$ & $1.5 \%$ \\
\hline $\begin{array}{l}\text { Yeilding was completed at the corrugated region } \\
\text { and spread over the entire reduced region. }\end{array}$ & Yeilding was more apparent. & $2 \%$ \\
\hline $\begin{array}{l}\text { The flange yeilding was extended and this } \\
\text { yeilding was apparent at tubular web in the } \\
\text { middle of connection part in the flange. }\end{array}$ & $\begin{array}{l}\text { Yeilding of the reduced region was followed by a } \\
\text { minor yeilding outside the reduced region near } \\
\text { the column face, and also before the reduced region. }\end{array}$ & $3 \%$ \\
\hline $\begin{array}{l}\text { Yeilding regions were extended and the flange local } \\
\text { buckling commenced inside the corrugated region. }\end{array}$ & $\begin{array}{l}\text { Yeilding of beam flange extended and then } \\
\text { slightly towards the flat web. }\end{array}$ & $4 \%$ \\
\hline $\begin{array}{l}\text { Yeilding was apparent at the tubular web in } \\
\text { connection corner part to flange. }\end{array}$ & $\begin{array}{l}\text { Yeilding became extensive adjacent to the } \\
\text { conection beam to column peneteration welds. }\end{array}$ & $5 \%$ \\
\hline $\begin{array}{l}\text { local buckling became extensive and the } \\
\text { yielding at the tubular web extended into the } \\
\text { beam depth }\end{array}$ & $\begin{array}{l}\text { A minor flaking was detected at the corrugated web } \\
\text { corner, near the beam flange and the flange local } \\
\text { buckling commenced outside the corrugated region; } \\
\text { this was then followed by web local buckling. }\end{array}$ & $6 \%$ \\
\hline $\begin{array}{l}\text { Lateral-torsional buckling of beam appeared in } \\
\text { the top flange of left beam, immediately after } \\
\text { the reduced region. }\end{array}$ & . & $7 \%$ \\
\hline $\begin{array}{l}\text { The flange yeilding was extended at depth and } \\
\text { width of tubular web and the amplitudes of the } \\
\text { flange buckling became more noticeable. Test } \\
\text { results show that the crack and rupture were } \\
\text { initiated at the top flange of left beam, } \\
\text { immediately after the reduced region. }\end{array}$ & $\begin{array}{l}\text { The amplitudes of the flange and web bukling } \\
\text { become more expensive and the right beam } \\
\text { top flange moved laterally, while it was in } \\
\text { comperession. }\end{array}$ & $8 \%$ \\
\hline $\begin{array}{l}\text { Test results show the cracks in the top flange of } \\
\text { left beam progressed down into connection of } \\
\text { the tubular web to flat web and crack and rupture } \\
\text { were initiated in the bottom flange of right beam, } \\
\text { exactly in the reduced region. }\end{array}$ & $\begin{array}{l}\text { The flange and web buckling grew rapidly and } \\
\text { the flange lateral movment became expensive, } \\
\text { cracks were found in the fillet welds at corners } \\
\text { of the corrugated plates near the left beam } \\
\text { bottom flange. }\end{array}$ & $9 \%$ \\
\hline
\end{tabular}

values are respectively 12,23 , and 36 for TW-RBS model in the reduced section zone at the same story drift. In comparison with AW-RBS, it represents an increase of plastic strain in the reduced section zone of the proposed model.

Normalized strain curve on different parts of tubular web in TW-RBS model is presented in Figure 11 in order to study the effects of accordion web. As clearly shown, strain profile in corrugated web has a significant decrease in all points in comparison with linear profile of strain distribution in beam web, and the accordion web behavior has caused great reduction of the axial strain of beam web at plastic hinge location. According to the curves, axial strain in the tubular web was increased close to the beam flange, while by taking distance from beam flange, the longitudinal strain of the web was highly decreased and became negligible. The absence of web in the flexural strain leads to the elimination of web participation in flexural capacity.

Evaluation of strain gained from the numerical analysis of the proposed models shows more concentration of plastic strain in the reduced section of the 


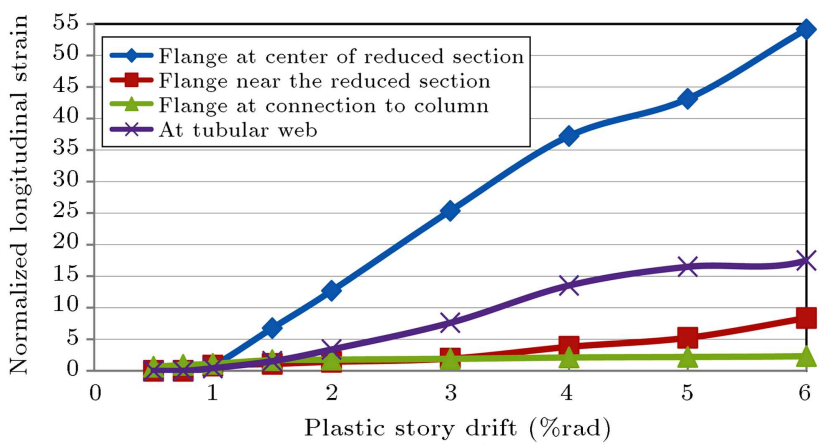

(a) TW-RBS model (proposed model)

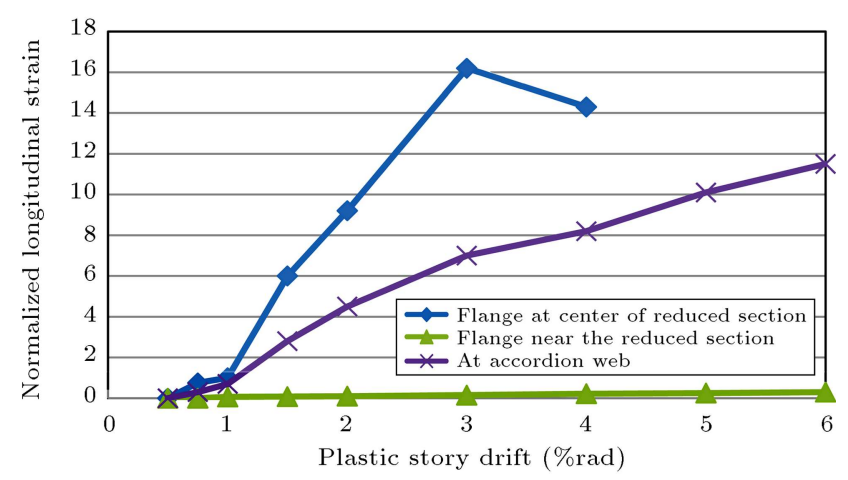

(b) AW-RBS model [20]

Figure 9. Normalized strain push versus story drift.

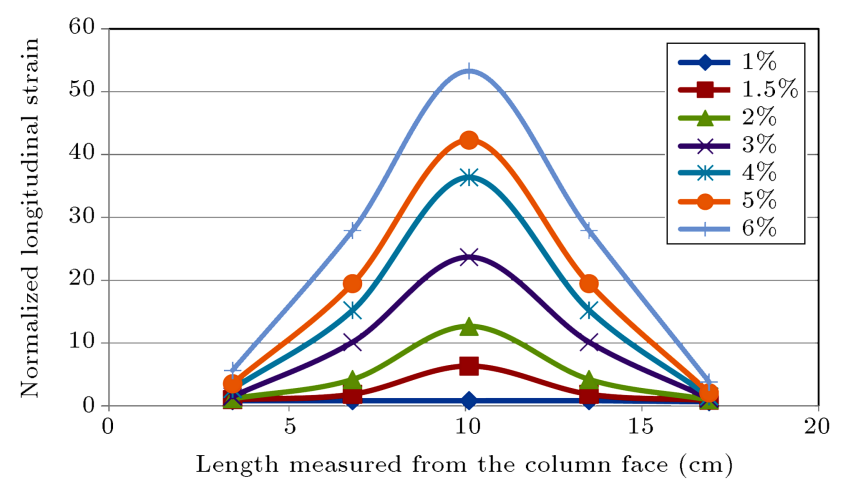

(a) TW-RBS model (proposed model)

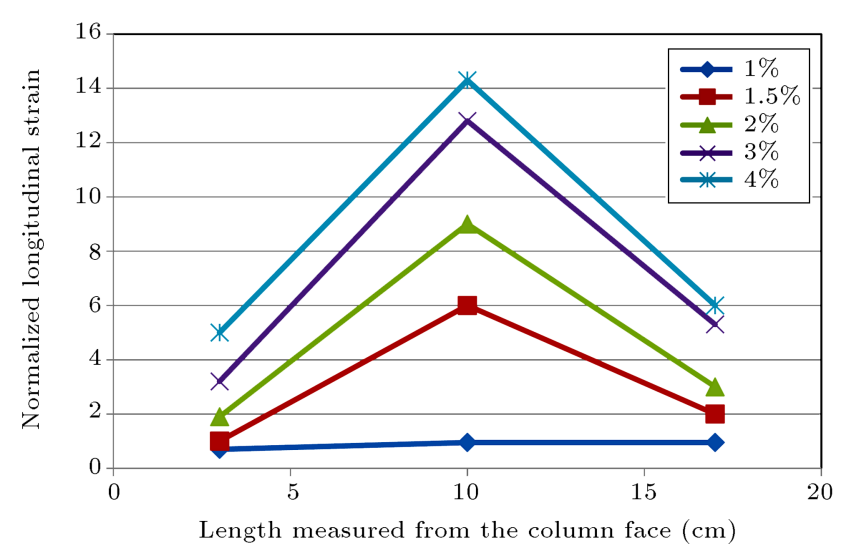

(b) AW-RBS model [20]

Figure 10. Envelope of normalized strain on the beam flange at different distances from the column face.

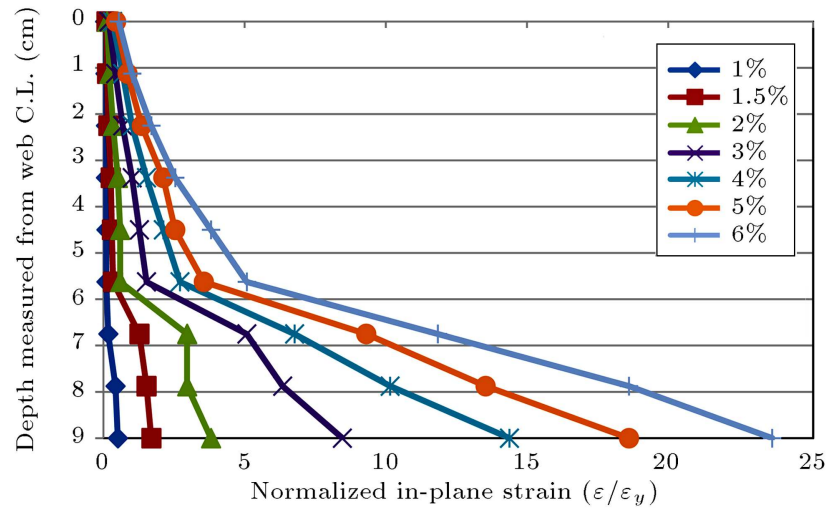

(a) TW-RBS model (proposed model)

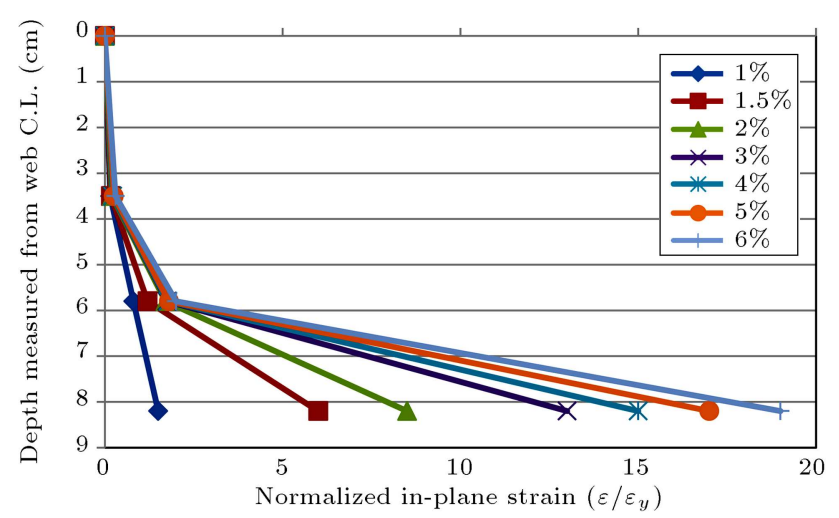

(b) AW-RBS model [20]

Figure 11. Envelope of normalized strain at different distances from the neutral axis.

proposed model compared to the previous experimental and numerical studies of AW-RBS, demonstrating more ductility for the proposed model.

\section{Conclusions}

In this study, a new type of RBS connection, TWRBS, was evaluated through cutting continuous web and replacement of that part with a tube. Overall, the numerical and experimental results demonstrated that TW-RBS provides significant ductility up to $8 \%$ story drift without reducing the bending strength at the column face. It is noteworthy that TW-RBS satisfies the 2010 AISC seismic provisions [23] and FEMA 350 [1] acceptance criteria up to $9 \%$ story drift. Moreover, a connection with TW-RBS was also provided with more strain and tension concentration in the reduced section of the flange compared to the connection proposed by Mirghaderi et al. [20]. In addition, the following are concluded:

- The results indicate that due to flexural strength reduction by replacing web in the proposed connection, using TW-RBS reduces the plastic strain demand near complete joint penetration welds and effectively concentrates the plastic strains within the reduced region; 
- The plastic hinge capacity can only be estimated in the reduced region based on the beam flanges, and the contribution of the beam web to the plastic hinge capacity is negligible because of the web accordion behavior;

- The most important feature of using the tubular web is to improve the out-of-plane stiffness about the beam longitudinal axis and also the flange stability condition due to the smaller width-to-thickness ratio of beam flange. Also, according to the numerical and experimental results, flange local buckling was detected inside the reduced region in TW-RBS connection;

- Tubular web provides a better condition in terms of low-cycle fatigue than accordion web because change of strain direction in arc shape of the tabular web section creates smaller angles compared to sharp corners of the accordion section.

Despite the acceptable seismic performance of the designed connection, the results may not necessarily be extrapolated to the deeper beams used frequently in moment frame constructions. Therefore, complementary experimental program in the next stage of this research is underway by authors for deep beams and further validation purposes.

\section{Acknowledgment}

Authors would like to thank the University of Tehran and the Islamic Azad University, Professor Hesabi Branch, for supporting this research.

\section{References}

1. Federal Emergency Management Agency, FEMA-350, Seismic Design Criteria for New Moment Resisting Steel Frame Construction, Washington DC (2000).

2. Federal Emergency Management Agency, FEMA$355 \mathrm{D}$ "State of the art report on connection performance", Washington DC (2000).

3. Chen, S.J. and Chao, Y.C. "Effect of composite action on seismic performance of steel moment connections with reduced beam sections", Journal of Construction Steel Research, 57, pp. 417-434 (2001).

4. Uang, C.-M. and Fan, C.-C. "Cyclic stability criteria for steel moment connections with reduced beam section", Journal of Structural Engineering, 127(9), pp. 1021-1027 (2001).

5. Nakashima, M. and Kanao, I. "Lateral instability and lateral bracing of steel beams subjected to cyclic loading", Journal of Structural Engineering, 128(10), pp. 1308-1316 (2002).
6. Jay-Shen, J.H., Astaneh-Asl, A. and McCallen, D. Use of Deep Columns in Special Steel Moment Frames, AISC, Steel Tips (2002).

7. Jones, S.L., Fry, G.T. and Engelhardt, M.D. "Experimental evaluation of cyclically loaded reduced beam section moment connections", Journal of Structural Engineering, 128(4), pp. 441-451 (2002).

8. Roeder, C.W. "Connection performance for seismic design of steel moment frames", Journal of Structural Engineering, 128(4), pp. 517-525 (2002).

9. Ricles, J.M., Fisher, J.W., Lu, L.-W. and Kaufmann, E.J. "Development of improved welded moment connections for earthquake-resistant design", Journal of Constructional Steel Research, 58, pp. 565-604 (2002).

10. Lee, C.H., Jeon, S.W., Kim, J.H. and Uang, C.M. "Effect of panel zone strength and beam web connection method on seismic performance of reduced beam section steel moment connection", Journal of Structural Engineering, 131(12), pp. 1854-1865 (2005).

11. Moslehi Tabar, A. and Deylami, A. "Instability of beams with reduced beam section moment connections emphasizing the effect of column panel zone ductility", Journal of Constructional Steel Research, 61(11), pp. 1475-1491 (2005).

12. Zhang, X. and Ricles, J.M. "Experimental evaluation of reduced beam section connections to deep columns", Journal of Structural Engineering, 132(3), pp. 346-357 (2006).

13. Zhang, X. and Ricles, J.M. "Seismic behavior of reduced beam section moment connections to deep columns", Journal of Structural Engineering, 132(3), pp. 358-367 (2006).

14. Han, S.W. and Moon, H.H. "Design equations for moment strength of RBS-B connection", Journal of Construction Steel Research, 65, pp. 1087-1095 (2009).

15. Pachoumis, D.T., Galoussis, E.G., Kalfas, C.N. and Efthimiou, I.Z. "Cyclic performance of steel momentresisting connections with reduced beam sectionsexperimental analysis and finite element model simulation", Engineering Structures, 32(9), pp. 2683-2692 (2010).

16. Wilkinson, S., Hurdman, G. and Crouther, A. "A moment resisting connection for earthquake resisting structure", Journal of Constructional Steel Research, 62, pp. 295-302 (2006).

17. Prasada-Rao, D.V. and Satish-Kumar, S.R. "RHS beam-to-column connection with web openingparametric study and design guidelines", Journal of Constructional Steel Research, 62, pp. 747-756 (2006).

18. Yang, Q. and Yang, N. "Seismic behaviors of steel moment resisting frames with opening in beam web", Journal of Constructional Steel Research, 65(6), pp. 1323-1336 (2009).

19. Elgaaly, M., Hamlton, R. and Seshadri, A. "Shear strength of beams with corrugated webs", Journal of Structural Engineering, 122(4), pp. 390-398 (1997). 
20. Mirghaderi, S.R., Torabian, S. and Imanpour, A. "Seismic performance of the Accordion-Web RBS connection", Journal of Constructional Steel Research, 66, pp. 277-288 (2010).

21. Saleh, A., Zahrai, S.M. and Mirghaderi, S.R. "Experimental study on innovative tubular web RBS connections in steel MRFs with typical shallow beams", Structural Engineering \& Mechanics, 57(5), pp. 71-88 (2016).

22. Morrison, M., Schweizer, D. and Hassan, T. "An innovative seismic performance enhancement technique for steel building moment resisting connections", Journal of Constructional Steel Research, 109, pp. 34-46 (2015).

23. American Institute of Steel Construction, AISC, Seismic Provisions for Structural Steel Buildings, Chicago (2010).

24. Engelhardt, M., Winneberger, T., Zekany, A. and Potyraj, T. "Experimental investigation of Dogbone moment connections", Eng. J. AISC, Fourth Quarter, pp. 128-139 (1998).

25. Eldib, M.E. "Shear buckling strength and design of curved corrugated steel webs for ridges", Journal of Constructional Steel Research, 65, pp. 2129-2139 (2009).

26. Eldib, M.E. "Buckling analysis of beams with corrugated webs", Proceeding of 5th International Conference on Civil and Architecture Eng. (ICCAE Conf), (2004).

27. Hamilton, R.W. "Behavior of welded girder with corrugated webs", Ph.D. Dissertation, University of Maine, Maine (1993).

\section{Appendix}

\section{Assessment of resistance mechanisms of the} tubular Web RBS connection $\left(T_{W-R B S}\right)$

To evaluate the axial resistance of tubular web in the reduced region and compare it with the axial resistance of a flat web, a cylindrical bar with the depth of the unit is considered. According to Figure A.1, the ultimate condition of a cylindrical bar under the effect of $P$ makes four hinges at the end points and the center point of the circular. Free body diagram of quarter segments can be considered due to the establishment of symmetry. Accordingly, by writing the moment balance equation at a plastic joint, $P_{\text {corr }}$ force can be obtained as follows:

$$
P_{\text {corr }}=\frac{8 M_{p c}}{D}=\frac{8 \frac{t_{c}{ }^{2}}{4} F_{y}}{D}=\frac{2 t_{c}{ }^{2} F_{y}}{D} .
$$

By taking the same height and letting $A_{f}=t_{f}$ for flat sheet, we have:

$$
P_{\text {flat }}=A_{f} F_{y}=t_{f} F_{y}
$$
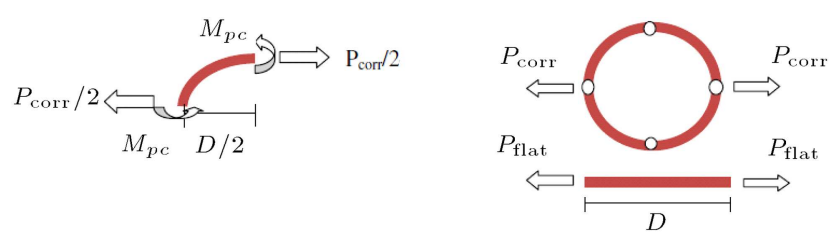

Figure A.1. Free energy diagram for a cylindrical bar and a flat bar to a depth of the unit.

Measurement of the impact on the resistance properties of tubular accordion web and a comparison between the tube resistance and flat web, Strength Degradation Factor (SDF) can be calculated as follows:

$$
\mathrm{SDF}=1-\frac{P_{\text {corr }}}{P_{\text {flat }}}=1-\frac{2\left(\frac{t_{c}}{t_{f}}\right)^{2}}{\left(\frac{D}{t_{f}}\right)} .
$$

Based on the equation above, SDF is a function of pipe diameter ratio to flat web and tube thickness ratio to flat web.

Beam plastic moment in the corrugated area can be written as a function of axial resistance $P_{\text {flat }}$ or $P_{\text {corr }}$. Letting $p(y)=-p$ for negative values of $y$ and $p(y)=p$ for positive values of $y$ in the web plastic state, and also the cross-section is symmetric about the neutral axis; plastic moment is calculated as follows:

$$
M=\frac{P h^{2}}{4} .
$$

In this case, $p$ is the axial strength and can be replaced by $P_{\text {corr }}$ or $P_{\text {flat }}$. Because the plastic moment of web section is equal to $Z_{\mathrm{web}} F_{y}$, then modulus of the plastic portion of web can be calculated as follows:

$$
\begin{aligned}
& M=\frac{P h^{2}}{4}=Z_{\mathrm{web}} F_{y}, \\
& Z_{\mathrm{web}}=\frac{P h^{2}}{4 F_{y}} .
\end{aligned}
$$

Since the plastic modulus calculated by the contribution of web directly depends on the inside axial strength, the ratio of the plastic modulus of the tubular web to plastic modulus of the flat web is $P_{\text {corr }} / P_{\text {flat }}$ proportionally.

In other words, the reduction factor of web plastic modulus is equal to SDF. According to the results, the plastic modulus of the I-shaped beam along the tubular area can be calculated as follows:

$$
Z_{A W S}=Z_{\text {flange }}+(1-\mathrm{SDF}) Z_{\mathrm{web}}^{\text {flat }}
$$

\section{Biographies}

Seyed Mehdi Zahrai was born in Tehran, Iran, in 1964. He received his BSc degree in Civil Engineering 
from Tehran Polytechnic in 1987, his MSc degree in Structural Engineering from the University of Tehran in 1990, and his PhD in Structural Engineering from the University of Ottawa in 1997. He has been a Professor at the School of Civil Engineering, University of Tehran, since 1999. He has authored many publications, including 10 books and more than 380 journals and conference papers, supervised about 140 theses and research projects, managed and directed many large steel and concrete building tower or bridge projects in design and construction phases, served a few conferences as the chairman, and has been a member of editorial board or reviewer in many international journals. Dr. Zahrai has been also a member of many scientific societies and innovation advisory committees in Iran, awarded a few times for teaching or research and uniquely recognized for about 300 workshops and educational sessions held on different aspects of seismic design, retrofit and construction of steel and concrete building and bridge structures.

Seyed Rasoul Mirghaderi was born in Esfehan, Iran in 1954. He received his BSc degree in Civil Engineering from the Sharif University, Iran, in
1976, and his MSc and $\mathrm{PhD}$ degrees in Structural Engineering from the Purdue University, USA, in 1980 AND 1981, respectively. He has been a Professor at the School of Civil Engineering, the University of Tehran, since 1987 . He has authored many publications including 11 books, more than 250 journals, and conference papers, so far supervised about 100 theses and research projects, managed and directed many large steel and concrete building tower projects in design and construction phases, and served a few conferences as the chairman. Dr. Mirghaderi has been also a member of many scientific societies and innovation advisory committees in Iran.

Aboozar Saleh was born in Tehran, Iran in 1979. He received his BSc in Civil Engineering from the Tehran Polytechnic in 2002, his MSc degree in Structural Engineering from the Sharif University, Iran, in 2004, and his $\mathrm{PhD}$ degree in Earthquake Engineering from the University of Tehran, in 2016. He has been an Assistance Professor at the Islamic Azad University Professor Hesabi Branch since 2005. He has authored more than 20 journal and conference papers. His research interests are seismic analyses and structural control. 